\title{
Solidaridad y compromiso social en
}

\section{dermatología}

La solidaridad, entendida como la unión de diferentes voluntades para conseguir el bien común, es un valor de gran trascendencia, que permite superar situaciones críticas, resistir con firmeza la adversidad y asumir grandes desafíos ${ }^{(1)}$. Es un factor de cambio que dignifica a los individuos y a la sociedad.

Reflexionando sobre el papel del dermatólogo en la construcción de una Colombia con mejores oportunidades para todos, preocupa que la mayoría de los especialistas esté concentrada en las principales ciudades del país, dejando desatendida una gran parte de la población. Son muchos los motivos, entre ellos, las expectativas individuales, la forma como hemos sido educados, las condiciones laborales y el nuevo ritmo de los tiempos, donde estamos confinados a las comodidades del mundo digital.

Como ejemplo de solidaridad y compromiso social, equipos de profesionales de la salud conformados por enfermeros, médicos, estudiantes de posgrado, dermatólogos y otras especialidades realizan brigadas para atender a los colombianos más vulnerables. Son varios los colegas que lideran estas acciones desde diferentes regiones del país y, además, algunos dermatólogos han elegido laborar en ciudades pequeñas.

En este número de la revista se resalta el trabajo de investigación de la Universidad de Caldas y la Universidad El Bosque, que reporta las características sociodemográficas, epidemiológicas y clínicas de los pacientes atendidos por dermatología en brigadas de la Patrulla Aérea Civil Colombiana (PAC), durante los años 2008-2018; en este período se realizaron 37 brigadas, cada una de 3 días, en 26 poblaciones de 14 departamentos de Colombia, que beneficiaron a cerca de 3000 pacientes, en su mayoría mujeres. Los trastornos cutáneos inflamatorios fueron los más frecuentes, y el acné fue el principal motivo de consulta.
La PAC es una organización sin ánimo de lucro que durante más de 50 años ha llevado atención médica gratuita a regiones apartadas del país y conserva registros de datos epidemiológicos de diferentes poblaciones colombianas, que constituyen un insumo valioso para la comprensión de la morbilidad dermatológica en áreas rurales de cinco de las seis regiones naturales del país. Con sus voluntarios y el traslado de equipos médicos, la PAC presta también asistencia quirúrgica y en desastres naturales. Colombia es una nación palpitante, de bellos paisajes y contrastes culturales, con grandes necesidades y dificultades de acceso a los servicios de salud. Cada uno de los participantes de estas brigadas regresó con otra mirada, con el alma llena de patria e invitándonos a repensar nuestra labor frente a los menos favorecidos.

Desde el lugar de privilegio que tenemos los dermatólogos por haber recibido una educación superior, el llamado es a mantener la vocación de servicio como eje 
fundamental del ejercicio médico. Para AsoColDerma y las diferentes universidades del país, el presente y futuro plantean la necesidad de ampliar la participación en programas de proyección a la comunidad. Agradecimiento y admiración a los docentes y residentes de la Universidad de Caldas y a todos aquellos que solidariamente contribuyen a la construcción de soluciones a los problemas de salud de nuestra población.

Margarita María Velásquez EDITORA

REVISTA DE LA ASOCIACIÓN COLOMBIANA DE DERMATOlogía Y CIRUGÍA DERMATOLÓGICA

PROFESORA, SECCIÓN DE Dermatología, Centro de INVESTIGACIONES DERMATOLÓGICAS (CIDERM)

FACUlTAD DE MEDICINA, UNIVERSIDAD DE ANTIOQUIA

\section{"Nunca dudes que un pequeño grupo de ciudadanos comprometidos y conscientes puede cambiar el mundo; de hecho, es lo único que siempre lo ha hecho".}

Margaret Mead Frase tomada de: https://www.patrullaaerea.org

\section{REFERENCIA}

1. El libro de los valores. $10^{\mathrm{a}}$ edición. Bogotá, Colombia: Casa editorial El Tiempo; 2013. 